\title{
Image-Based Sexual Abuse in a Culturally Conservative Nigerian Society: Female Victims' Narratives of Psychosocial Costs
}

\author{
Richard Abayomi Aborisade ${ }^{1}[0$
}

Accepted: 18 January 2021 / Published online: 23 January 2021

(C) The Author(s), under exclusive licence to Springer Science+Business Media, LLC part of Springer Nature 2021

\begin{abstract}
Background In the last few years, many countries have introduced laws combating image-based sexual abuse (IBSA), colloquially known as "revenge pornography." However, the significant growth in the body of literature on the legal perspectives on IBSA, and the media coverage of high profile cases have not been equally met with appreciable victimization studies. Meanwhile, the need for a victim-centered approach in studying IBSA in Nigeria is underscored by the pervasiveness and normalization of sexual violence as a result of societal attitudes about gender and sexuality in the country. Therefore, this study explored the social and psychological implications of IBSA victimization.

Methods Using qualitative methods, 27 adult women whose sexual images have been non-consensually shared publicly through online channels were purposively selected and interviewed for the study, between September 2019 and April 2020, and a thematic analysis of the participants' narratives carried out.

Results Victims of IBSA were found to be subjected to higher social condemnation, stigmatization, and isolation based on greater attribution of blames to them by their social network. Evidences of institutional re-victimization were documented. Victims also reported self-blame, paranoia, anger, guilt, depression, suicidal ideation and attempt in dealing with the abuse, secondary victimization, and social isolation.

Conclusion IBSA victims are faced with peculiar social and psychological consequences which separate them from victims of other forms of sexual abuse. The study suggests a review of appropriate laws and social policies to prevent IBSA, deploy more victim support services and perpetrator programs, and protect victims from secondary victimization.
\end{abstract}

Keywords Conservatism $\cdot$ Image-based sexual abuse $\cdot$ Rape culture $\cdot$ Revenge porn $\cdot$ Victimization

\section{Introduction}

Image-based sexual abuse (IBSA), popularly called "revenge pornography," is a term that is used in describing a pattern of behaviors that involves the non-consensual creation, distribution, or the threats to distribute nude or sexual images (videos and photographs) of people (Henry et al., 2019). Legal restrictions have been placed on the practice across the world. For example, in England and Wales, the practice is proscribed under the Criminal Justice and Courts Act 2015, with similar legislations passed in Australia and the USA. Similarly, in Nigeria, the increase in the practice

Richard Abayomi Aborisade

aborisade.richard@oouagoiwoye.edu.ng

1 Department of Sociology, Faculty of Social Sciences, Olabisi Onabanjo University, P.M.B. 2002, Ogun State, Ago Iwoye, Nigeria has led to the passage of the Cybercrimes Act of Nigeria 2015 that forbids IBSA. However, the significant growth in the body of literature on the legal perspectives on IBSA (Levendowski, 2014; Patton, 2015; Kirchengast \& Crofts, 2019), and the media coverage of high profile cases have not been matched with appreciable victimization studies, in spite of the widespread acknowledgement that revenge pornography or IBSA has the potential of severely harming victims and society (Goudsmit, 2017; Henry et al., 2019; Branch et al., 2017; Scott \& Gavin, 2018).

In what appears to be one of the first well-known cases of IBSA in Nigeria, a female student was reportedly gangraped by five male students of Abia State University, with the videotaped incident posted online on August 17, 2011 (BBC Report, 2011). In the video, which lasted for more than an hour, the victim could be heard pleading to be killed because she could no longer bear the pains, after her earlier pleas to be spared fell on deaf ears. In spite of the 
public outrage generated by this incident, and several civil societies demand for justice, the Abia State Police Command suspended the investigation into the gang rape following its reported finding that "the girl-victim consented to the rape" (Vanguard, 2011). The Assistant Commissioner of Police in charge of the command was quoted to have said that there was no sign of the girl-victim resisting the rape. However, this claim was refuted by Sahara Reporters (2011), which reported that the victim and her mother were forced into disclaiming the rape, out of fear for their lives and social stigmatization.

The apparent growth and increase in the incidence of image-based sexual abuse in Nigeria has further aggravated the pervasiveness of sexual crimes in the country (Daily Post, 2017; Premium Times, 2020; The Nation, 2019), despite the availability of laws criminalizing IBSA. Beyond these legal instruments and the effectiveness of law enforcement, scholars have identified sexual stereotypes, perceptions, and attitudes of the Nigerian society towards sexual crime victimization as being responsible for the growth of sexual violence (Aborisade \& Vaughan, 2014; Ezechi, et al., 2016; The World Bank, 2019). The body of literature on sexual crimes in Nigeria has affirmed that the country has a rape culture (Aborisade, 2014; Amaka-Okafor, 2013; Nwafor \& Akhiwu, 2019), which is a sociological concept that describes settings where rape and other forms of sexual assault are pervasive and normalized as a result of societal attitudes about gender and sexuality (George \& Martínez, 2016; Krishnan, 2015). Scholars identified victim blaming, denial of widespread rape, sexual objectification, slut-shaming, trivializing rape and refusing to acknowledge the harm caused by sexual violence as some of the attributes that manifest in the Nigerian society and hinder victims from reporting sexual victimization (Aborisade, 2016; Aborisade \& Vaughan, 2014; Amaka-Okafor, 2013; Chiazor et al., 2016). Therefore, concerns have been raised about the effectiveness of laws forbidding IBSA in the face of negative social response to victims' reporting of sexual crime.

On the background of the high number of unreported sexual crimes in the country, fuelled by victims' fear of negative social responses (Aborisade, 2014; Awosusi \& Ogundana, 2015), it is imperative to examine the social reactions that trail IBSA from victims' perspective and its psychological impacts on them. The importance of a study on IBSA victimization, beyond the usual sexual abuse victims' studies, is premised on the peculiarities of the nature and patterns of IBSA and the assumption that it will generate a different social response. The current study is novel and extends extant literature on intimate partner violence and sexual crimes, by investigating the social and psychological implications of IBSA and other electronic forms of women abuse from victims' perspective. The study is particularly relevant in a society like Nigeria, with deep-rooted sexually conservative culture, in which sex is perceived to be more subject to self-control, and youths are socialized to abstain from premarital sex (Aborisade, 2014; Awosusi \& Ogundana, 2015). Consequently, victims of sexual crimes are often blamed and stigmatized for precipitating their sexual victimization. Although, the term "victim" is used throughout this article to refer to those who are the subjects of different forms of IBSA, however, the author acknowledges the ambiguity inherent in the use of this term, as not all people identify with it (Kirchengast \& Crofts, 2019). Also, this study favored the use of the term "image-based sexual abuse" to the commonly used "revenge pornography," in order to accommodate a much broader array of online and image-based sexual victimizations, and focus on victims of abusive behaviors by those who misuse intimate imagery.

\section{Theoretical Background: Feminism, Male Support Theory and Nigeria's Sexual Conservatism}

Feminists have notably drawn on the theoretical literature on gender and sexuality to further analyze the gendered nature of IBSA as an important supplement to the emerging empirical studies on the phenomenon. In this study, the male support theory will be adopted. The adoption of male support theory is informed by the focus of this study on female victims, and not that the theory is adequate to explain victimizations of other categories of victims such as male heterosexuals, and lesbian, gay, bisexual, and transgender (LGBT) persons. Male support theory is a theoretical perspective heavily influenced by feminist schools of thought and the masculinities. The theory posits that the dissemination of IBSA is a means of "doing masculinity" in a culturally specific way (Messerschmidt, 1993). Furthermore, studies in masculinities have shown that the decision to be violent towards women and others is a factor of class, gender, and race/ethnic relations that structure the resources available to accomplishing what men feel would cater to their masculine identities (DeKeseredy \& Schwartz, 2005). Dominant or hegemonic practices or discourses, which include woman abuse, are learned through personal and interpersonal interactions with significant others, such as parents, teachers, journalists, politicians and entertainers (DeKeseredy \& Schwartz, 2016). In spite of this, the all-male patriarchal subculture remains one of the most important agents of socialization (DeKeseredy \& Schwartz, 2013). In such a peer group, membership, irrespective of race/ethnic composition or social class, tends to promote and legitimize image-based sexual abuse of women.

The development of peer support theory was initially premised on the explanation of the reason that men, as a result of their attachment to patriarchal and abusive male peers, perceived some college female dating partners as 
appropriate targets for physical, sexual, and psychological assaults (DeKeseredy, 1988). However, this perspective was considered to be overly focused on social psychological factors, and as a result, DeKeseredy and Schwartz (1993) made a revision in order to consider broader social forces. They postulated that in rape-supportive culture, abusive patriarchal men have male friends that share their values and beliefs about promoting abuse of women, especially those considered to be a threat to male patriarchal authority. There are attachments that are provided by those men to other abusive men, and resources that entail specific emotional and verbal support.

Nigeria has been identified as a rape-supportive culture, where the complex interplay between existing social structures, socialization and conventional attitudes in the country favor gender inequalities (The World Bank, 2019; Africa Network for Environment \& Economic Justice, 2016). In the country, the socialization of men is often directed towards making them dominant, aggressive, and even violent. Masculinity itself becomes identified with these characteristics of strength and authority (Ogunola, 2018). Structural powers within the Nigerian society have also been attributed to creating gendered norms and inequalities that are associated with the concept of men as active and controlling, and women as passive and vulnerable (Babalola, 2014; Etobe et al., 2015).

The foundation of young peoples' attitudes and expectations in respect of their identity and role are created by these gendered norms. In the light of this, young men are reported to have a sense of entitlement towards their female partners and may resort to IBSA or other forms of electronic abuse if they feel their exclusive right over their women is being threatened (Edinyang \& Angiating, 2018; Onwutuebe, 2019). For example, a popular Lagos-Nigeria based pastor, Chris Omatsola, was reported to have released online a sex videotape with his former lover, which they had both recorded consensually (The Punch, 2019). The female partner disclosed that the pastor released the video after unsuccessful attempts to blackmail her into forced marriage, as she decided to quit the relationship. After the video was leaked, she was quoted to have said "He (referring to the pastor) said now that my pictures and videos were out there, no man would want to look my way again, that it was best we got married." This is premised on the belief that a woman whose sexual image has been shared publicly will become unattractive and unacceptable to other men to take as a wife, as an outcome of their social stigmatization.

Feminists have mainly explored the phenomenon of "slut shaming," which is a term that is used to describe the social condemnation of those who transgress deeply embedded, puritanical societal beliefs and values about sexuality, particularly female sexuality (Ringrose \& Renold, 2012; Sweeney, 2017). In the Nigerian society, women are usually held up against a double standard that applies unequally to them, and they are often derided as "willing victims" in sexual crimes against them. Also, while boys and men are rewarded and praised for heterosexual sexual contacts, women and girls are derogated and stigmatized for similar behaviors (Aborisade, 2014; Kreager \& Staff, 2009). Therefore, the peer support theory provides a veritable explanation for the reasons men in the Nigerian society could resort to sexual violence based on their attachment to patriarchal and abusive male peers (DeKeseredy \& Schwartz, 1993). Also, the general awareness of female victims' reluctance to report sexual violence against them, as a result of possible social stigmatization (Aborisade, 2014), may foster the growth of sexual crimes in the country, and, in particular, hinder the reporting of IBSA.

\section{Incidences of Image-Based Sexual Abuse and the Nigerian "Rape Culture"}

Rape and other forms of sexual violence against women in Nigeria are pervasive and normalized as a result of societal attitudes about gender and sexuality (Chiazor, et al., 2016; Tade \& Udechukwu, 2020). This makes some scholars to imply that Nigeria has a "rape culture" (Amaka-Okafor, 2013; Ezechi et al., 2016). Krishnan (2015) identified the following behaviors as attributable to the reign of rape culture in a society: sexual objectification, victim blaming, trivializing rape, and refusing to acknowledge the harm caused by sexual violence, denial of widespread rape, and slut-shaming. As pointed out by empirical studies, the attitudinal response of the Nigerian society to incidences of rape or sexual harassment exhibits some of the behaviors that Krishnan identified (Ezechi et al., 2016; Nwafor \& Akhiwu, 2019).

By extension, female victims of revenge porn are usually subjected to more ridicule and blamed for playing sexual role in the act that has been made public (The Nation, 2019). In some instances, the blame and shame are inflicted by organizations and institutions where such victims work or are affiliated. In 2019, a 300 level (third year) female student and her 400 level (fourth year) boyfriend, both of Babcock University, a private Christian co-educational institution, were shown on a leaked video having sex in a hospital's private ward, where the boyfriend was admitted for drug rehabilitation (The Nation, 2019). It was reported that the boyfriend recorded the sex video with the consent of the girl, but the boy later sent the video to a third party who uploaded it on the Internet. This led to the termination of the female partner's studentship by the university, on the grounds that she "violated university rules and regulation" (Premium Times, 2019). The male student had earlier been expelled from the school for drug-related offence and "other grievous misconduct" (Premium Times, 2019). 
The decision of the university to expel the female victim of the revenge porn was greeted with a lot of criticism by a section of the Nigerian society, who perceived the punishment of the female student as an act of slut-shaming. In the words of Sweeney (2017), slut-shaming is the practice of criticizing people, especially women and girls, who are perceived to have violated expectations of behavior and appearance regarding issues that relate to sexuality. According to Ezechi et al. (2016), Nigeria is a culturally conservative society, where young women are subjected to sexual "double standards," in which young men's activeness is labelled as the "norm," while sexually active young women are derogatorily labelled as "sluts" or "loose." In addition, women are not expected to subject themselves to the ridicule of having sex in the public space or privately outside their matrimonial homes, or pre-marital sex, let alone recording it (Adekaniye, 2019). Therefore, victims of IBSA are blamed on the basis of such moral grounds. Questions were further raised why the educational institution that is meant to reform and guide, could decide to expel a student at a time she mostly needed reformation and guidance (The Nation, 2019).

The scapegoating and punishment of female victims of sexual assault, rape, and IBSA has been attributed as the key factor to the low reportage level of sexual crimes committed against women in the country (Aborisade, 2014; Nwafor \& Akhiwu, 2019; The World Bank, 2019). As a result, the prevailing culture of silence that often trails incidences of sexual victimization in the country, due to the fear of being socially stigmatized, has been identified as a major factor that may render efforts at curbing IBSA growth ineffective (Awosusi \& Ogundana, 2015; Omoregie, 2018). However, the prevailing culture of silence was recently confronted by a 58-year-old Nigerian music legend, Salawa Abeni, who shared her own nude pictures on Instagram and Facebook in April 2020, after being blackmailed on the release of these pictures online for an undisclosed sum of money (Premium Times, 2020). She equally shared the screenshots of her chats with the blackmailer to resist the overtures from the blackmailer, who was subsequently arrested by officers of the Rapid Response Squad, Lagos.

Meanwhile, Henry et al. (2019) identified perpetrators who non-consensually create, distribute, or threaten to distribute nude or sexual images, as intimate partners, family members, friends, acquiantances, and persons unknown to the victim. These perpetrators have been reported to have different motivations and diverse reasons for their actions, which include monetary gain, social notoriety, retribution, voyeurism, and sexual gratification. These images may be self-created by the victim as a "selfie" or produced consensually in the context of an intimate relationship. In 2017, a former Miss Anambra State, Chidimma Okeke's sex tape with her lesbian partner was leaked on various social media (Daily Post, 2017). In her narration, Miss Okeke stated that the sex video was one of the activities expected of the contestants of the beauty pageants and the organizers only used the video to blackmail her when she challenged their breach of the terms of their contract (Daily Post, 2017). According to her, the organizers used the video to blackmail her in order to make her do their biddings and only released the video when she insisted on retrieving the car she won in the competition, after it had earlier been withdrawn from her. There was, however, no report of arrest or prosecution of the perpetrators of the non-consensual video leak, in spite of available legal instrument against such practice in the country.

\section{The Present Study}

Existing studies on sexual crimes and victimization in Nigeria have dealt with different dimensions of sexual violence, ranging from child to the elderly sexual abuse (Aborisade \& Shontan, 2017; Adedayo \& Aborisade, 2018; Akinlusi, et al., 2014; Tade \& Udechukwu, 2020). However, the subject of revenge pornography or IBSA in the country has been minimally researched, in spite of the apparent increase in the incidences of online leak of non-consensual nude pictures and video images in the country. Meanwhile, the understanding of the context of IBSA and the peculiarities of social and psychological costs on IBSA victims has been suggested as a key step in supporting victims (Henry, et al., 2019; Scott \& Gavin, 2018). The current study, therefore, set out to examine the context within which incidences of IBSA occur, the nature, source, perpetrator-victim relationship, motives, and post-abuse experiences to victims.

As against studies that used the terminology "revenge pornography" (Flynn et al., 2016; Goudsmit, 2017; Kirchengast \& Crofts, 2019), the present study used IBSA. This is based on the study's aim to include an array of behaviors and motivations that go beyond perpetrators that are motivated by revenge when they share nude or sexual images of others without their consent. Also, this study extended its focus beyond sharing of sexual images by jilted ex-lovers that are seeking revenge against former partners. In addition, the term "revenge porn" was considered inappropriate for this study as it appears to minimize the harm done to victims by failing to acknowledge that the practice is a form of abuse, and the term arguably connotes victim blaming because it implies that the victim has done something to provoke the wrath of the offender. Therefore, in order to accommodate a broader examination of non-consensual sharing of images of women, and the post-abuse experiences of the victims as regards social and psychological implications, the concept IBSA was considered appropriate for the study. The three behaviors considered as IBSA in this study are: 
1. the recording, creation or taking of nude or sexual images without consent;

2. the sharing, distribution, dissemination or posting of nude or sexual images; and/or

3. the issuing of threats to share nude or sexual images.

\section{Method}

The unexplored, emotive, and complex nature of this study informed the adoption of qualitative approach. The aim of the research is to capture IBSA victims' breadth of experience, as well as their viewpoints, rather than the commonality and dominant discussion on revenge pornography or other forms of IBSA. Meanwhile, in order to ensure that the research questions are properly addressed, sufficient structure was drawn in the interviews, while flexibility was allowed to pursue the thought processes of the participants.

\section{Compliance with Ethical Standards}

In the conduct of this study, efforts were made to adhere to ethical standards applicable to research involving human subjects, while there is no conflict of interest which could have brought any form of bias to the process of the research and the report generated therefrom. All through the recruitment and interview periods, considerable emphasis was laid on the voluntary nature of this study, while the researcher was alert to any form of distress from the participants during the interviews. Also, after the interviews, the participants were given information sheets that contained the details of local and national sexual violence and counseling services.

The participants were requested to complete informed consent forms that were provided to them, together with the study information, both electronically and in hard copy, at least $48 \mathrm{~h}$ before the interviews. The confidentiality and anonymity of the participants were very important to the study, and they were assured of these. As a result, only the author knew those that took part in the study, while all data were kept in accordance with the regulations of Olabisi Onabanjo University. Finally, approval for the study was granted by the Social Research Ethics Committee of the Faculty of Social Sciences, Olabisi Onabanjo University.

\section{Sample Participants}

The study's community of interest were female adults who had experienced or were experiencing non-consensual pornography or IBSA that had become known to their friends, family members (including step-family members and families-in-laws), neighbors and/or colleagues. Based on the objective of the study, those who were still being blackmailed for the release of their videos, pictures or other images were considered inappropriate for the study. Besides, capturing information-rich cases was considered important due to dearth of studies in the topic area. Therefore, conscious attempts were made to ensure that participants with varied experiences, beliefs and attitudes were recruited for the study. In order to achieve this, maximum variation sampling was utilized. This sampling technique turns the challenge of heterogeneity between individual cases in small samples from ostensible weakness to strength, (Creswell, 2013).

The eligibility for participation in the study was the attainment of 16 years of age at the time of the interview. In addition, the IBSA experienced must fit into Sect. 24 of the Cybercrimes Act of Nigeria (2015) definition of the sexual abuse, and this was screened for before the interview, based on the self-report of the prospective participants. The use of English was mainly adopted for communication during the interviews, although some participants occasionally used some words and phrases from their local languages. They were, however, requested to translate them for clarity.

\section{Procedures and Data Collection}

The research had no natural groups or organizations to approach to directly elicit participation for the study. As a result, the bid to optimize diversity led to the adoption of varied approaches, which were deployed for a period of 8 months (September 2019-April, 2020). These included advertising on various social media platforms, posters in community venues, and Web-based advertisements. Meanwhile, in an effort to ensure the safety of both the interviewer and interviewees, physical interviews were conducted in community premises. As the interview period extended into the COVID-19 pandemic and lockdown period, more interviews were conducted over the telephone, Skype, and other video-call technologies, except for participants that insisted on face-to-face interviews. After obtaining the consent of the participants, the researcher requested them to complete a socio-demographic questionnaire, which was set to inform the analysis, contextualize the participants' narratives, and offer information about the diversity of the sample in order to guide recruitment strategies.

Data collection was conducted through interviews with the use of semi-structured interview guide, which was developed from findings of previous studies on related subjects. The interview guide covered areas like perception of sexual abuse, relationship with abusers, types of IBSA experienced, post-abuse experience (psychological and social backlash) and coping mechanism. In adhering to principles of qualitative research, the initial topic guide 
evolved so that insights gained in early interviews could inform subsequent ones (King \& Horrocks, 2010). The author conducted all the interviews, ranging from 40 to $1 \mathrm{~h}$ $30 \mathrm{~min}$, and they were all audio-recorded. The audio-records were transcribed verbatim and the anonymized transcripts were imported into NVivo version 12 (a software that is used to support the management and organization of qualitative data). The analysis and interviews were conducted, simultaneously, while recruitment continued until the point of saturation was reached. This point is described as the stage of "diminishing return where increasing sample size no longer contributes new evidence" (Ritchie et al., 2003). Overall, 27 interviews were conducted with female victims of various IBSA across different parts of Nigeria.

\section{Data Analysis}

All recorded interviews were transcribed and analyzed using thematic techniques. Thematic analysis is a method that emphasizes identifying, analyzing and interpreting patterns or meaning (or "themes") within qualitative data (Braun \& Clarke, 2006). As soon as the author familiarized himself with the data, he engaged in line-by-line coding using the NVivo software. The grouping of initial descriptive codes into themes was done and then refined using constant comparison: a process used throughout the analysis, while comparing units of data with the entire data set and emerging theories, for the modification of constructs and relationships between them (Glaser \& Strauss, 1967). As it is in all forms of qualitative analysis, these phrases are not linear but iterative, attempting to distil and hone in a cyclical fashion (King \& Horrocks, 2010). The author discussed with experts in the fields of sociology, psychology, and law all through the process, and, in particular, considered case examples and data coding together in order to refine the themes and provide some validation for the analysis.

An assessment of the consistency of the coding, intercoder reliability check, was done with the assistance of three academics in the fields of psychology, sociology and law, who had initially helped with the construct validity check for the research instruments. They were requested to act as independent coders and their familiarity with the study goals considerably reduced the time expended on their training in using the coding and categorization protocols. About $40 \%$ sample of the total content of the transcripts was selected for the intercoder reliability test. Afterwards, the coding of the coders were compared and discussed. The Krippendorff's alpha coefficient was 0.918 for the agreement of the four coders. This is considered to be above accepted reliability standards, thus indicating that the content analysis in this study is reliable. Finally, the author met with the independent coders to resolve any discrepancies in order for all applied codes to be mutually agreed upon.
In the presentation of the findings, exemplar quotes from the narratives of the participants were used to illustrate and support the findings. The brackets after each quote contain such information as the chosen pseudonym by the participants, their town of residence and employment status.

\section{Results}

\section{Sample Description}

Data for the study was obtained from 27 participants, between September 2019 and April 2020. In-depth interviews, consisting of nine face-to-face, 11 over the telephone voice calls, four WhatsApp video calls, and three Skype video calls, were conducted within the period. The higher number of interviews conducted through electronic means, as compared to face-to-face, was based on some participants' insistence on telephone interview and the restriction of movement during COVID-19 lockdown. The majority of the participants were students of tertiary institutions (14/27), followed by those (9) who were employees of private and public organizations. Their ages ranged from 16 to 45 years, with the majority (21/27) falling within 16-30 years. They were all Nigerians, mostly of Yoruba ethnic affiliation (17/27), have post-secondary education (24/27), and were never-married singles (21/27). All participants were residents except one, who participated from the UK, as at the time of data collection. There were more than 27 different accounts given by the participants, as three of them reported being victims of IBSA more than once.

\section{Findings}

In providing context to the themes that follow, it was considered imperative for the readers to understand the behaviors that the perpetrators of IBSA had exhibited towards their partners, ex-partners or victims. At the point of recruitment, prospective participants had been informed that all forms of non-consensual sharing of intimate, private and sexual images by someone else (known or unknown) were included within the scope of this study. That is, whether the recording or taking of nude pictures were consensual or taken as "selfie," as long as the sharing or distribution was nonconsensual, they were eligible for the study. During the interview process, participants recognized that they only knew a fraction of what constitute IBSA, and were only aware that intimate partners are the ones in the position to subject their partners to IBSA. Consequently, they were informed that IBSA could also be perpetrated by family members, friends, acquaintances and persons unknown to them. 


\section{Nature, Motivations, and Perpetrator-Victim Relationship with Abuser}

Based on the study design and objective, all the 27 participants have had their nude or sexual images shared or distributed online without their consent. On the nature of IBSA experienced by the participants, 13 of them had videos of their sexual intercourse (8) and nude dancing (5) shared or distributed to people without their consent; 11 had images of their complete nude pictures distributed (with their faces included in the picture), while 3 had their semi-nude pictures with their faces shared without their consent. From the eight participants that indicated their sex videos were shared, six indicated that the recorded sex was with their dating partners while two stated that the recording was of a forced sex with an acquaintance. Meanwhile, out of the six with dating partners, only two reported that the video was taken with their consent at the time of the sexual intercourse. The remaining four stated that they were unaware of the recording until their partners shared the videos with them at the point of issuing threats (3), and when it was already shared online (1).

Six out of the eleven whose complete nude pictures were shared indicated that they took the pictures on their own and sent to their dating partners, while three indicated that their dating partners took the pictures with their consent; although, one of them said she had wanted the picture taken without her face included. One of the remaining two participants in this category said her roommate (a female) "took the picture and shared with some guys in my class because she wanted to get back at me." The last participant (Tolani) described how a nonacquaintance that lived in the same compound with her recorded her while she was dressing up in her room: "he was just outside my window...it was dark outside, and the light in my room was on, with my curtain set aside." Finally, all the three participants whose semi-nude pictures were shared stated that they took the pictures themselves and sent to their dating partners, who then shared the images with other people without their consent. They recounted they were all topless in the picture, with their bare breasts and faces recorded.

All the 14 participants (5 with nude dancing videos, 6 complete nude, and 3 semi-nude pictures) that sent their pictures/videos to their intimate partners pointed out that they did so on the request of their partners. Patricia, a third year university student, stated that after sending series of her nudes to her boyfriend without her including her face on the images, her boyfriend pleaded with her to include her face "in order for him to have meaningful arousal from the video." She continued: ...it was during the lockdown (restrictions of movement occasioned by COVID-19 pandemic) and we had been spending weeks apart from each other. I eventually succumbed to his wishes to have me record myself naked and acting sex moves and dancing seductively on the video just to satisfy him. (Patricia/23/student)

The participants perceived diverse motives behind the perpetrators' actions of taking, keeping and sharing their nude pictures. Ten participants indicated voyeurism as one of such motives: a situation in which their dating partners kept the images for their self-entertainment; and also shared them with their friends to establish their (perpetrators') sexual conquests or exploits. Concerning the manner of sharing, six of them indicated that their complete nude pictures (2) and sex videos with their partners (4) were sent by their partners through text messages, while the remaining four stated that their partners showed friends from their phones and it became known to them that other people had seen their nude and sex videos. Ngozi narrated how she came to find out that her sex video had been shared by her boyfriend:

A guy in my class walked up to me and started smiling, looking at me lustfully, and suddenly asked, 'can I also have a share of your honey pot?' I was embarrassed, as some of my classmates were there. I was about walking away from him when he pulled me back and said 'all that you are covering under your cloth has been exposed to us. I have seen your nakedness in totality; I have seen you in sex action; all I need now is to also have a feel of you.

(Ngozi/25/student)

Ngozi stated that a female acquaintance later showed her the video from her phone. Seven participants indicated that their sexual image exposure was based on relationship retribution for leaving their intimate partner (4), or double dating (3). Atinuke, a self-employed grocery shop owner, stated that she was in an abusive relationship that she needed to leave, but her dating partner was adamant and refused letting her go. He threatened her with her sex videos and nude pictures in his possession.

Meanwhile, this is a person that had numerous girls he sleeps with. Whenever I challenged him, he would slap and beat me up. Not only that, he would forcefully take the money I used in running my business at any given opportunity, and stopped me from keeping friends. I was so suffocated but I could not leave him out of fear he would publicly expose my pictures and videos with him. Eventually, my friends asked me to call his bluff and leave him for my own safety. He made good 
his threat by sharing my sex video with him and nude pictures on his WhatsApp status. From there, it was eventually distributed among my social circle, friends, family and so on.

(Atinuke/32/self-employed)

Another five participants stated that they were subjected to sextortion in which the perpetrators used intimate images to coerce them into sexual acts or retain sexual access to them. Beatrice described how she was subjected to multiple abuses in a bid to prevent the public sharing of her sex video with her dating partner:

...I was in my second year and met this guy, who asked me out. I never knew he had this evil intention. He was a cultist (a campus-based secret group). Within the week I started dating him, we had sex in his room. Unknown to me, he had placed a recording device somewhere in his room. I never knew I was recorded until I was approached by a guy who showed me the video and threatened to Bluetooth it to the whole campus if I did not have sex with him. I was scared. I confronted my boyfriend who denied being involved in the recording and did nothing to assist me. I eventually had sex with this guy only to be approached by another guy afterwards. In short, I had sex with five of them when I found out they were in cohort with my boyfriend. At that time, I had stopped dating him. I could not go on like that, so I left the school. They started sharing my sex video even after I had withdrawn from the school. It was eventually sent to my father's phone...

(Beatrice/31/unemployed)

Three participants pointed out that the primary motive of the perpetrators was to obtain monetary benefits from them. One of the three was Tolani, who was recorded naked by a non-acquaintance from outside her window, while dressing up in her room.

Initially, he asked me for sex, but I pleaded with him to take money instead. He then asked for $\mathrm{N} 100,000$, which I could not afford. I gave him N30,000, then another $\mathrm{N} 20,000$ weeks later. I was still looking for the balance when I saw that he had already released the video.

(Tolani/29/unemployed)

In two instances, the female victims were not the ones in direct contact with the perpetrators before the images were shared and they had no knowledge of the threats until the pictures/videos got shared. In one of such instances, Alimat, a final year student of a northern Nigeria university, expressed that her dating partner was fond of keeping her nude pictures and videos of their sexual intercourse on his phone and laptop just to "view for the fun of it whenever he feels like." However, one of his friends stumbled on these images and copied some of them, and started blackmailing her boyfriend by demanding for money from him. He later shared the images when her boyfriend could not meet with his terms.

\section{Post-Abuse Reactions from Social Network (Family, Friends, Colleagues, and Significant Others) and Other Social Costs}

Participants were requested to narrate the observed reactions from their social network that knew about the sharing of their nude images, either by physically seeing the image or being informed about the image exposure. All the 27 participants affirmed that their shared nudities were made available to their friends and other non-family associates. However, 16 of the participants indicated that their parents, siblings, and close family members saw their shared sexual images, while five of them stated that their family members only "heard" about the public sharing of these images without actually seeing them.

Generally, all the 27 participants indicated that they were all blamed by those that came across their sexual images in one way or the other. This report was equally given by those that had no knowledge about being recorded or photographed. Furthermore, the participants stated that they were commonly blamed for engaging in premarital sex, sex video, nude "selfie," sharing nude pictures with dating partners, and being careless when naked (for Tolani whose nude picture was taken from outside her room). Those whose immediate families were privy to the sexual images explained that they were subjected to sustained condemnation, rebuke, abuse, chastising, denials, and isolation. Beatrice, who was subjected to sextortion before her sexual image was made public and sent to her father, stated as follows:

...I was grounded at home for months. I was physically assaulted by my father multiple times, at the slightest provocation and even when there was no provocation from my side. During that period, anytime he talked about it and I remained silent, I would still be beaten for being silent. If I talked, I would be beaten for talking. I got tired of living. Nobody to turn to at home, as everybody dissociated from me and treated me with scorn that I brought the family name into disrepute. I was treated with so much hatred to the extent that I started hating myself.

(Beatrice/31/unemployed)

Beatrice could not continue with her education as a result of the incident, as her father refused sending her back to school. Two years after the incident, she eventually went for a vocational study to learn tailoring. Aside from Beatrice, five other participants explained that the public sharing of 
their sex videos led to the end of their tertiary education. Three of such participants, who were students of private universities, were expelled by their school authorities over the incidents. Meanwhile, two participants left their schools and enrolled in other schools, but lost years spent in their previous institutions.

Dorcas, an ex-banker, was married with two children, as at the time she engaged in an extramarital affair with her colleague at work, who recorded their sex video. Her "jealous" dating partner at work eventually uploaded their sex images on the social media, after she had left him for another colleague. She described the backlash, which drove her into attempting suicide:

...I lost my home, my husband sent me away and I could not plead or resist. I left everything and everything left me - my job, my children, my friends, my church, my parents and family. I left the town I was based (Lagos) and traveled to another thinking I would be able to start afresh. But I couldn't. My world crashed and I attempted suicide by taking rat poison in a hotel room in Calabar. As the poison affected my intestine, the pain was much so I screamed, but not for help. However, I got the help I didn't bargain for, as hotel attendants opened my door and rescued me. That made my matter worse, as my case became public knowledge the more, through newspapers' and blogs' reports. It was easy to link my suicide attempt to my sex video that went viral.

(Dorcars/42/Social worker)

Dorcas eventually left the country for the UK, from where she participated in the interview. Dorcas, who was a banking officer prior to the release of her sex video, further stated that she stopped going to work, even before she was summoned by her bank's disciplinary committee. An invitation she did not honor: "they only wanted to fulfil all righteousness; I was already going to get the boot so why bother."

As applicable to Dorcas, six other participants also indicated they were employed and lost their source of livelihood to the incident of their sexual image exposure. One of them was a working student who also lost her studentship, as she could no longer finance her education without work. However, a participant who was working in the public sector stated that she was able to retain her job, and was not invited before any disciplinary panel as a result. She, however, stated that she became a subject of sexual harassments as a result of her private picture leakage. According to her, male colleagues and superiors kept making unwanted sexual overtures, intimidation and threats to her. Overall, 19 participants stated that they were compelled to change their residential location as a consequence of the leak, including those that lost their studentship or voluntarily withdrew from schools and work.

\section{Perceived Psychological and Emotional Reaction}

Participants expressed different degrees of psychological and emotional damage that these experiences had on them during the blackmail periods and, especially, after the images were shared publicly. Generally, those who received threats from their intimate partners described the severe emotional pain associated with betrayal of trust and self-blame. They also explained the amount of fear they nursed in anticipation of the social backlash that would follow the leak.

After the images had been shared to their social network, 24 participants described experiencing mental stress, leading to paranoia, anger, guilt, depression and suicidal ideation. Out of the 11 participants that indicated they had considered committing suicide, it was only Dorcas that attempted it. The remaining 10 participants indicated that their religious commitments at the time and the fear of suicide process and death restrained them from going ahead to attempt suicide. They, generally, stated that they were apprehensive of what would become of them in the afterlife. Furthermore, all the participants expressed that they had exhibited deep sense of shame after their images were publicly shared, with 23 of them stating they could not go out of their apartments for some periods of time. "I left my apartment to stay with a friend and I remained indoors for weeks: no church, no lectures, nowhere," Bolatito volunteered.

Seventeen of them, who stated that they used to be active on social media and other social networks, revealed that they had to shut down their accounts, while only five of them opened new accounts with disguised identities. The majority of the participants also indicated that they had to deal with trust issues with their romantic partners since the incidents. One of such participants is Mary, who explained that she ended her last dating relationship because her boyfriend merely requested for her nude picture. She added, "anytime a man refers to me as being 'sexy,' my mood usually changes to fear, apprehension and anger...the fact that my nakedness had been seen by a lot people, I felt like I have been publicly raped." Constance shared similar feeling, as contained in the excerpt below.

You won't know the way it feels, when you are in a public place like the market, and whenever anybody looks at you, your mind starts telling you that the person has seen your nakedness...everything about you...you feel everyman looking at you is trying to unbutton your shirt with his eyes and have sex with you. When people stare at your direction, you feel they have seen you naked even when you have never seen them before.

(Constance/28/employed)

Virtually all the participants indicated they still feel occasional psychological and emotional effects of 
their IBSA, in the form of shame, guilt, powerlessness, withdrawal, low self-esteem, and feelings of worthlessness. These reoccurring psychological and emotional distress were reported by the participants to be mostly caused by the continuous taunting and references made about their IBSA experience by family members, friends and significant others. From the narratives of the participants, it was evident that their adverse post-abuse psychological and emotional experiences were aggravated by the negative social reactions that trailed the sharing and distribution of their sexual images.

\section{Discussion}

The current study deployed victim studies approach to explore the social and psychological experiences of female victims of IBSA in a culturally conservative Nigerian society. Gleaning from the accounts of women and young girls whose nude or sexual images have been shared and viewed or made aware to their families, friends, colleagues and the general public, the findings from this study suggest that victims of IBSA in Nigeria are exposed to peculiar and far-reaching social and psychological costs. Past research has found that victims of sexual violence and abuse in Nigeria are usually subjected to blame and condemnation for their real and perceived roles in making themselves vulnerable to sexual assault (Aborisade \& Vaughan, 2014; Awosusi \& Ogundana, 2015). However, the present study revealed that victims of IBSA are subjected to more social condemnation, stigmatization, and isolation than victims of rape, based on greater attribution of blame to IBSA victims.

With regard to the perpetrator-victim relationship and the motivation for IBSA, the study found intimate partners, male and female acquaintances, and strangers to be perpetrators of IBSA. This aligns with existing studies on perpetrators of revenge pornography (Henry et al., 2019; Scott \& Gavin, 2018), which identified intimate partners as the most prevalent perpetrators involved in sharing and distributing nude and sexual images of their female partners. However, as against extant literature that identified relationship retribution as the main motivation behind these actions (Bates, 2016; Borrajo \& Gámez-Guadix, 2015), which largely prompt the use of the term "revenge pornography" (Branch, et al., 2017; Burris, 2014), this study found voyeurism to be more significant. The majority of the participants perceived their intimate partners' exposure of their nude images to be informed by their desire for sexual gratification, enjoyment, entertainment, and show-off of male power and conquest to their friends. Other relevant reasons for the perpetrators' acts are relationship retribution, sextortion and sexploitation.

The study reported considerable social consequences that victims of IBSA are made to suffer as a result of their sexual image exposure. These include public shame, ridicule, taunting, and harassment. Although existing studies have reported the social costs of revenge porn on victims (Bates, 2016; Branch, et al., 2017), the magnitude and dimensions of losses experienced by these victims, as found in this study, appear to be higher. Victims of IBSA are exposed to social stigma, ostracism, and isolation from their social networks of friends, schoolmates, colleagues, and close associates, while they are subjected to chastisement, condemnation, and denials of privileges by their family members. Significant losses that participants reported include truncation of their education at tertiary levels (either by self-withdrawal, parental refusal to continue sponsorship or expulsion by school authorities), loss of jobs (voluntary or termination of appointment), loss of marriage and intimate relationship, restriction of movement, loss of social lives (voluntary or forced withdrawal from social media, social gatherings and religious meetings), sexual harassment, social stigma and isolation.

A pertinent finding of this study is the high level of institutional ostracization that victims of IBSA suffered as a result of their victimization. Institutions of higher learning and work organizations were found to have expelled and terminated the appointments of victims as a further reflection of victim-blame that pervades Nigerian society (Aborisade, 2014; Ezechi et al., 2016; Nwafor \& Akhiwu, 2019). IBSA victims' experience of institutional ostracism, as found in this study, is in consonance with the recently reported case of Babcock University student who was expelled in her third year after her sex act with her intimate partner was made public (Premium Times, 2019). This decision by the university management elicited reactions by social groups and analysts about the appropriateness or otherwise of the verdict of the university authority on the female victim (Adekaniye, 2019; Adediran, 2020). However, the fact that the laws on sexual violence in Nigeria often focus on definitions and punishment of offenders with little or no compensation or protection for victims make survivors of sexual abuse to be vulnerable to secondary victimizations.

The study found a disturbing level of psychological and emotional reactions from participants, largely as a result of the social costs that trailed their IBSA experience. Extant studies have documented the psychological and mental health implications of being victims of revenge porn and IBSA (Bates, 2016; Dir \& Cyders, 2015; Flynn, et al., 2016). IBSA victims were found to be subjected to protracted psychological trauma, from the time they were blackmailed to the time their sexual images were publicly shared, and 
moments after the exposure. Aside from the deep sense of betrayal they felt, participants also reported self-blame, paranoia, anger, guilt, depression, suicidal ideation and attempt. Emotional problems like feelings of powerlessness, withdrawal, low self-esteem, and worthlessness were also largely reported. The findings of the study on the psychological implications of IBSA suggest that victims endure negative social perceptions and attitudes towards them that extend their trauma and delay mental recovery from their abusive experience.

\section{Implications for Social, Public Policy, and Further Research}

The findings from the study highlight the need for the Nigerian government to review the law forbidding imagebased sexual crimes under the Cybercrimes Act of Nigeria 2015 and other laws against sexual violence in the country in order to include protection for victims. At present, victims of IBSA in the country are vulnerable and subjected to double victimization, based on the psychological and social costs of their experience. The loss of studentship, jobs, and other forms of institutional victimization and discrimination that trail IBSA should be addressed by the law. Also, there is a need for more effective enforcement of the laws against IBSA to deter potential perpetrators.

There is a need for the Nigerian government, as well as other stakeholders, to deploy more victim support services and perpetrator programs to check the growth and spread of IBSA in the country. In particular, reporting channels should be made more accessible to reflect victims' diversity: to include the use of telephone, in-person and online media. Orientation and public campaigns should be given to potential perpetrators, through the mass media, on the inappropriateness of sharing or receiving nude or sexual images. This prevention campaign should also focus on consent and respectful relationship.

Future research needs to triangulate the perspectives of IBSA perpetrators and bystanders - those that receive and share nude images, and corporate organizations-with those of the victims, so that IBSA can be considered from multiple viewpoints that will broaden our understanding around the nature of their experiences, as well as potential barriers to education and other prevention strategies.

\section{Conclusion}

Previous research on sexual violence in Nigeria has presented an array of social and psychological effects of sexual victimization in a culturally conservative country. However, the experiences of the IBSA victims, in terms of the peculiar social and psychological consequences of their victimization, are yet to be documented. This research has captured rich descriptions of the experiences of IBSA victims in terms of their abusive treatment, sexual images exposure, and people's reactions within their social circle. Also, the study revealed the peculiar consequences of the institutional victimization they experienced, the psychological stress that they faced as a result, and the associated social costs. The different motives of IBSA perpetrators and the forms of the abuse have also been reported. To this end, providing recognition to the victims' predicaments and abusive treatments would significantly address the spread of the practice by government, nongovernment agencies, counseling services, parents, and other social support groups. This is, indeed, essential to effective intervention program, as it appears not entirely obvious to everyone that IBSA or revenge porn victims did not bring their misfortune upon themselves. Therefore, an analysis of the harms and wrongs imposed on them is warranted.

Author's Contribution Author is solely responsible for the article.

Data Availability Research data not deposited.

\section{Compliance with Ethical Standards}

Conflict of Interest The author declares that there is no conflict of interest.

\section{References}

Aborisade, R. (2014). Barriers to rape reporting for Nigerian women: The case of female university students. International Journal of Criminology and Sociological Theory, 7(2), 1-14.

Aborisade, R. (2016). The influence of rape myth acceptance and situational factors in defining sex and labelling rape among female university students in Nigeria. African Journal of Criminology and Justice Studies, 9(1), 154-170.

Aborisade, R. A., \& Vaughan, F. A. (2014). The victimology of rape in Nigeria: Examining victims' post-assault experiences and adjustment patterns. African Journal for the Psychological Study of Social Issues, 17(2), 140-155.

Aborisade, R., \& Shontan, A. (2017). Motivations and mechanism of child sexual abuse: The narratives of adult male offenders in Nigerian prisons. Ife Psychologia, 25(1), 244-265.

Adedayo, S., \& Aborisade, R. (2018). Sexual abuse of elderly women in Nigeria: A sociological exposition of an emerging crime. The Nigerian Journal of Anthropology and Sociology, 16(2), 13-21.

Adediran, A. (2020). Cyberbullying in Nigeria: Examining the adequacy of legal responses. International Journal for the Semiotic of Law. https://doi.org/10.1007/s11196-020-09697-7.

Adekaniye, M. (2019). Babcock lady: A victim of revenge porn or decadence? The Guardian. Retrieved May 12, 2020, from https://guardian. ng/life/babcock-lady-a-victim-of-revenge-porn-or-decadence/. 
Africa Network for Environment \& Economic Justice. (2016). Why is there so much rape in Nigeria today? Lagos: ANEEJ. Retrieved from http://www.aneej.org/much-rape-nigeria-today/.

Akinlusi, F., Rabiu, K., Olawepo, T., Adewunmi, A., Ottun, T., \& Akinola, O. (2014). Sexual assault in Lagos, Nigeria: A five year retrospective review. BMC Women's Health, 14(115), 1-7.

Amaka-Okafor, V. (2013). Nigeria has a rape culture too. Guardian Africa Network. Retrieved April 14, 2020, from http://www. theguardian.com/world/2013/jan/14/nigeria-rape-india-culture.

Awosusi, A. O., \& Ogundana, F. C. (2015). Culture of silence and wave of sexual violence in Nigeria. AASCIT Journal of Education, $1(3), 31-37$.

Babalola, A. (2014). Gender inequality: Nigerian and international perspectives. British Journal of Arts and Social Sciences, 17, $167-174$.

Bates, S. (2016). Revenge porn and mental health: A qualitative analysis of the mental health effects of revenge porn on female survivors. Feminist Criminology, 12(1), 22-42.

BBC Report. (2011). Cyber anger at Nigeria gang rape footage. Retrieved April 27, 2020, from https://www.bbc.com/news/worldafrica-15032228.

Borrajo, E., \& Gámez-Guadix, M. (2015). Cyber dating abuse: Prevalence, context and relationship with offline dating aggression. Psychological Reports: Relationships \& Communications, 11(2), 565-585.

Branch, K., Hilinski-Rosick, C., Johnson, E., \& Solano, G. (2017). Revenge porn victimization of college students in the United States: An exploratory analysis. International Journal for Cyber Criminology, 11(1), 128-142.

Braun, V., \& Clarke, V. (2006). Using thematic analysis in psychology. Qualitative Research in Psychology, 3(2), 77-101.

Burris, A. (2014). Hell hath no fury like a woman porned: Revenge porn and the need for a federal nonconsensual pornography statute. Florida Law Review, 66(6), 2325-2359.

Chiazor, I., Ozoya, M., Udume, M., \& Egharevba, M. (2016). Taming the rape scourge in Nigeria: Issues and actions. Gender \& Behaviour, 14(3), 7764-7785.

Creswell, J. (2013). Data collection. Qualitative inquiry and research design: Choosing among five approaches (3rd ed.). London: Sage.

Daily Post. (2017). Miss Anambra sex scandal: How it all happened Chidinma Okeke. Retrieved April 11, 2020, from https://dailypost. ng/2017/06/29/miss-anambra-sex-scandal-happened-chidinmaokeke/.

DeKeseredy, W. S. (1988). Woman abuse in dating relationships: The relevance of social support theory. Journal of Family Violence, $3,1-13$.

DeKeseredy, W. S., \& Schwartz, M. (1993). Male peer support and woman abuse: An expansion of DeKeseredy's model. Sociological Spectrum, 13, 393-413.

DeKeseredy, W. S., \& Schwartz, M. (2005). Masculinities and interpersonal violence. In M. S. Kimmel, J. Hearn, \& R. Connell (Eds.), Handbook of studies on men and masculinities (pp. 353366). Thousand Oaks, CA: Sage.

DeKeseredy, W. S., \& Schwartz, M. (2013). Male peer support and violence against women: The history and verification of a theory. Boston, MA: Northeastern University.

DeKeseredy, W. S., \& Schwartz, M. D. (2016). Thinking sociologically about image-based sexual abuse: The contribution of male peer support theory. Sexualization, Media, \& Society, 1-8. https://doi. org/10.1177/2374623816684692.

Dir, A., \& Cyders, M. (2015). Risks, risk factors, and outcomes associated with phone and Internet sexting among university students in the United States. Archives of Sexual Behaviour, 44(6), $1675-1684$.

Edinyang, S., \& Angiating, L. A. (2018). Gender discerment and the implication on Nigerian policy. Global Journal of Educational Research, 17, 113-119.
Etobe, E. I., Ikpi, E. N., Ezikeudu, C. C., \& Etobe, U. (2015). The socialization process as bane of gender inequalities in Nigeria. International Journal of Science and Research, 4(11), 1540-1543.

Ezechi, O. C., Musa, Z. A., David, A. N., Wapmuk, A. E., Gbajabiamila, T. A., Idigbe, I. E., \& Ujah, I. A. (2016). Trends and patterns of sexual assaults in Lagos south-western Nigeria. The Pan African Medical Journal, 24(224), 261. https://doi.org/ 10.11604/pamj.2016.24.261.9172.

Flynn, A., Henry, N., \& Powell, A. (2016). More than revenge: Addressing the harms of revenge pornography. Melbourne: Monash University.

George, W. H., \& Martínez, L. J. (2016). Victim blaming in rape: Effects of victim and perpetrator race, type of rape, and participant racism. Psychology of Women Quarterly, 26(2), 110-119. https:// doi.org/10.1111/1471-6402.00049.

Glaser, B., \& Strauss, A. (1967). The constant comparative method of qualitative analysis. In B. Glaser \& A. Strauss (Eds.), The discovery of grounded theory: Strategies for qualitative research (pp. 101-158). Chicago, IL: Aldine Publishing Company.

Goudsmit, M. (2017). Revenge pornography: A conceptual analysis Undressing a crime of disclosure. Masters Thesis, Leiden University.

Henry, N., Flynn, A., \& Powell, A. (2019). Responding to 'revenge pornography': Prevalence, nature and impacts. Criminology Research Grants.

King, N., \& Horrocks, C. (2010). Interviews in qualitative research. London: Sage.

Kirchengast, T., \& Crofts, T. (2019). The legal and policy contexts of 'revenge porn' criminalisation: the need for multiple approaches. Oxford University Commonwealth Law Journal, 19(1). https://doi. org/10.1080/14729342.2019.1580518.

Kreager, D. A., \& Staff, J. (2009). The sexual double standard and adolescent peer acceptance. Social Psychology Quaterly, 72(2), 143-164. https://doi.org/10.1177/019027250907200205.

Krishnan, K. (2015). Rape culture and sexism in globalising India. Sur - International Journal on Human Rights, 12(22), 255-259.

Levendowski, A. (2014). Using copyright to combat revenge porn. New York University Journal of Intellectual Property and Entertainment Law, 3(2), 422-446.

Messerschmidt, J. (1993). Masculinities and crime: Critique and reconceptualization. Lanham, MD: Roman \& Littlefield.

Nwafor, C., \& Akhiwu, W. (2019). Medicolegal analysis of sexual assault victims in Benin. Nigeria. Nigerian Journal of Clinical Research, 8(13), 10-17.

Ogunola, A. (2018). Socialization and the Nigerian child: Context and implications. East African Scholars Journal of Education, Humanities and Literature, 1(1), 40-46.

Omoregie, P. (2018). Revenge Porn and the Nigerian Law. Lagos: Manifield Solicitors.

Onwutuebe, C. J. (2019). Patriarchy and women vulnerability to adverse climate change in Nigeria. Sage Open, 1-7. https://doi. org/10.1177/2158244019825914.

Patton, R. (2015). Taking the sting out of revenge porn: Using criminal statutes to safeguard sexual autonomy in the digital age. Georgetown Journal of Gender and the Law, 16(2), 407-444.

Premium Times. (2019). Babcock University speaks on viral sex video of former students. Retrieved June 4, 2020, from https:// www.premiumtimesng.com/news/more-news/364323-babcockuniversity-speaks-on-viral-sex-video-of-former-students.html.

Premium Times. (2020). How I obtained nude photos of popular musician, Salawa Abeni - Suspect. Retrieved June 21, 2020, from https://www.premiumtimesng.com/entertainment/music/ 395493-how-i-obtained-nude-photos-of-popular-musician-salawaabeni-suspect.html.

Ringrose, J., \& Renold, E. (2012). Slut-shaming, girl power and 'sexualisation': thinking through the politics of the international SlutWalks with teen girls. Gender and Education, 24(3), 333-343. https://doi.org/10.1080/09540253.2011.645023. 
Ritchie, J., Lewis, J., \& Elam, G. (2003). Designing and selecting samples. In J. Ritchie \& J. Lewis (Eds.), Qualitative research practice: A guide for social science students and researchers (pp. 77-108). London: Sage.

Sahara Reporters. (2011). Abia University Gang Rape Scandal: Abia Government Lies Exposed; As Crime Scene Is Identified. Retrieved May 12, 2020, from http://saharareporters. com/2011/09/23/abia-university-gang-rape-scandal-abiagovernment-lies-exposed-crime-scene-identified-\%E2\%80\%A8.

Scott, A. J., \& Gavin, J. (2018). Revenge pornography: the influence of perpetrator-victim sex, observer sex and observer sexting experience on perceptions of seriousness and responsibility. Journal of Criminal Psychology, 8(2), 162-172. https://doi. org/10.1108/JCP-05-2017-0024.

Sweeney, B. (2017). Slut Shaming. In N: K. L., The SAGE Encyclopedia of Psychology and Gender. Sage Publications. https://doi. org/10.4135/9781483384269.

Tade, O., \& Udechukwu, C. (2020). Characterizing rapists and their victims in select Nigeria newspapers. IntechOpen. https://doi.org/10.5772/ intechopen.91705.
The Nation. (2019). When private matters go viral. Retrieved June 23, 2020, from https://thenationonlineng.net/when-private-mattersgo-viral/.

The Punch. (2019). Tamara and I had more than 10 sex tapes, Pastor Omatsola claims. Retrieved June 4, 2020, from https://punchng. com/tamara-and-i-had-more-than-10-sex-tapes-pastor-omatsolaclaims/.

The World Bank. (2019). Gender-based violence: An analysis of the implications for the Nigeria for Women Project. Washington: International Bank for Reconstruction and Development/The World Bank.

Vanguard. (2011). ABSU gang rape: Victim agreed to be raped Police. Retrieved June 14, 2020, from https://www.vanguardngr. com/2011/10/absu-gang-rape-victim-agreed-to-be-raped-police/.

Publisher's Note Springer Nature remains neutral with regard to jurisdictional claims in published maps and institutional affiliations. 